\title{
THE PROPAGATION OF FLOOD SHOCK MODEL ON THE STEEP MOUNTAINOUS AREA COMBINED WITH GEOMETRICAL INFORMATION SYSTEM
}

\author{
Ki Ho Park ${ }^{1)}$ and Muneo Hirano ${ }^{2)}$ \\ ${ }^{1)}$ Department of Civil Engineering, Kyungdong College, 712 - 749 Hayaug, Korea \\ 2) Department of Civil Engineering, Kyushu University, Fukuoka, 812, Japan
}

(Received: 27 December 1995; Accepted: 31 January 1996)

\begin{abstract}
In this study the two dimensional hydrodynamic model to simulate the propaga tion of flood shock on the steep mountainous area have been developed. This model is formu lated by a hydrodynamic system with the assumption of unsteady flow as steady flow which can reduce computation time. The numerical computation for this model is executed by use of the eight point implicit scheme. The Incremental Dynamic Programming(IDP) technique is adopted for the optimization of grid size during the computation. The model is applied to compute the propagation of flood shock on the steep mountainous area located in southern part of the Korea. Comparison of the results between the proposed assumption model and the general type of two dimensional model indicates the proposed model is nearly as good as, and computationally much faster, than the general two dimensional.
\end{abstract}

Key Words : Two dimensional routing model, Flood shock model, GIS

\section{INTRODUCTION}

A two dimensional hydrodynamic model has been developed to simulate the propagation of flood shock on the steep mountainous area. The numerical computation for this model is executed through the 8 point implicit scheme. The geometrical information system for real basin is applied to determine the wa tershed of one or more target cells situated on a speci fied surface. The model is applied to simulate the propagation of the flood shock of the Wichon IHP representative area.

\section{THEORY OF PROPOSED MODEL}

A number of one dimension model of propagation of flood have been developed and these model can predict the propagation of flood in a channel accu rately (Park, 1995a; Park and Jee, 1994). A one di mensional model are possible for simulating propa gation of flood shock in a channel but is impossible to simulate the spreading of flood shock in a basin area due to two dimensional characteristics of flood prop agation (Park and Hirano, 1995; Park 1995b). There is some two dimensional model for this, and is need to be improved with the simple equation as well as with the use of accuracy numerical approximation technique. The equation for two dimensional un steady free surface flow, the governing equations are expressed in conservation form as equation (1).

$$
\begin{aligned}
& \frac{\partial \mathrm{U}}{\partial \mathrm{t}}+\frac{\partial \mathbf{E}}{\partial \mathrm{x}}+\frac{\partial \mathbf{F}}{\partial \mathrm{y}}+\mathbf{S}=0 \\
& \mathbf{U}=\left[\begin{array}{c}
\mathbf{h} \\
\mathbf{u h} \\
\mathbf{v h}
\end{array}\right], \mathbf{E}=\left[\begin{array}{c}
\mathbf{u h} \\
\mathbf{u} \\
\mathbf{0 . 5 g ^ { 2 }} \\
\mathbf{u v h}
\end{array}\right],
\end{aligned}
$$

$$
\mathbf{F}=\left[\begin{array}{c}
\mathbf{v h} \\
\mathbf{u v h} \\
\mathbf{v}^{2}+0.5 g^{2} h^{2}
\end{array}\right], \mathbf{S}=\left[\begin{array}{c}
0 \\
-\operatorname{gh}\left(S_{o x}-S_{f x}\right) \\
-\operatorname{gh}\left(S_{o y}-S_{f y}\right)
\end{array}\right]
$$

where $\mathrm{h}$ is flow depth, $\mathrm{u}$ is velocity component in $\mathrm{X}$ direction, $\mathrm{v}$ is velocity component in $\mathrm{Y}$ direction, $\mathrm{g}$ is acceleration due to gravity, $S_{\text {ox }}, S_{\text {oy }}$ are bed slopes in $\mathrm{X}$ direction and $\mathrm{Y}$ direction respectively, and $\mathrm{S}_{\mathrm{fx}}, \mathrm{S}_{\mathrm{fy}}$ are friction slopes in $\mathrm{X}$ direction and $\mathrm{Y}$ direction re spectively.

In general case, the bed slope ( $S_{\text {ox }}$ and $S_{\text {oy }}$ ) and the friction slope ( $\mathrm{S}_{\mathrm{f}}$ and $\mathrm{S}_{\mathrm{fy}}$ ) in $\mathrm{X}$ and $\mathrm{Y}$ direction is ex pressed as

$$
S_{f x}=\frac{n^{2} u \sqrt{u^{2}+v^{2}}}{h^{0.75}}, S_{f y}=\frac{n^{2} \mathbf{v} \sqrt{\mathbf{u}^{2}+\mathbf{v}^{2}}}{h^{0.75}}
$$

where $\mathrm{n}$ is Manning's roughness coefficient. By as suming the flow is steady, the governing equations for two dimensional steady flow is expressed in con servation form as approximation model shown in equation (3).

$$
\begin{aligned}
& \frac{\partial \mathbf{E}}{\partial \mathbf{x}}+\frac{\partial \mathbf{F}}{\partial \mathbf{y}}+\mathbf{S}=0 \\
& \mathbf{E}=\left[\begin{array}{c}
\mathbf{u h} \\
\mathbf{u}^{2}+0.5 \mathbf{g h}^{2} \\
\mathbf{u v h}
\end{array}\right], \mathbf{F}=\left[\begin{array}{c}
\mathbf{v h} \\
\mathbf{u v h} \\
\mathbf{v}^{2}+0.5 \mathbf{g h}^{2}
\end{array}\right], \\
& \mathbf{S}=\left[\begin{array}{c}
0 \\
-\operatorname{gh}\left(\mathbf{S}_{\mathrm{ox}}-\mathbf{S}_{\mathbf{f x}}\right) \\
-\operatorname{gh}\left(\mathbf{S}_{\mathrm{oy}}-\mathbf{S}_{\mathbf{f y}}\right)
\end{array}\right]
\end{aligned}
$$


vector term of $\mathbf{U}, \mathbf{E}, \mathbf{F}, \mathbf{S}$ is divided by two components and equation (1) is written as

$$
\begin{aligned}
& \frac{\partial \mathbf{U}_{1}}{\partial \mathrm{t}}+\frac{\partial \mathbf{E}_{1}}{\partial \mathbf{x}}+\frac{\partial \mathbf{F}_{1}}{\partial \mathbf{y}}+\mathbf{S}_{1}=0 \\
& \mathrm{U}_{1}=\left[\begin{array}{c}
0.5 \mathrm{~h} \\
\mathbf{u h} \\
0
\end{array}\right], \mathrm{E}_{1}=\left[\begin{array}{c}
0.5 \mathrm{uh} \\
\mathbf{u}^{2}+\underset{5 \mathrm{gh}^{2}}{0} \\
0
\end{array}\right], \\
& F_{1}=\left[\begin{array}{c}
0.5 v h \\
\mathbf{u v h} \\
0
\end{array}\right], S_{1}=\left[\begin{array}{c}
0 \\
-g h\left(S_{o x}-S_{f x}\right) \\
0
\end{array}\right] \\
& \frac{\partial \mathrm{U}_{2}}{\partial \mathrm{t}}+\frac{\partial \mathrm{E}_{2}}{\partial \mathrm{x}}+\frac{\partial \mathrm{F}_{2}}{\partial \mathrm{y}}+\mathrm{S}_{2}=0 \\
& \mathrm{U}_{2}=\left[\begin{array}{c}
0.5 \mathrm{~h} \\
0 \\
\text { vh }
\end{array}\right], \mathrm{E}_{2}=\left[\begin{array}{c}
0.5 \mathrm{uh} \\
0 \\
\mathrm{uvh}
\end{array}\right] \text {, } \\
& \mathrm{F}_{2}=\left[\begin{array}{c}
0.5 \mathrm{vh} \\
0 \\
\mathbf{v}^{2}+0.5 \mathrm{gh}^{2}
\end{array}\right], \mathrm{S}_{2}=\left[\begin{array}{c}
0 \\
0 \\
-\mathrm{gh}\left(\mathrm{S}_{\mathrm{oy}}-\mathrm{S}_{\mathrm{fy}}\right)
\end{array}\right]
\end{aligned}
$$

The vector components of flow $\mathbf{U}$ is determined by the discrete points of the variables $(w, y, t)$ through the equations (4) and (5). To make accurate and ef fective a two dimensional simulation model, the com putational scheme for calculating the computational grid size is carefully treated. In this study the proposed 8 point implicit scheme was applied to compute the accurate result. The time derivatives are approx imated by forward different quotient centered be tween the ith or $i+1_{\text {th }}$ points along the $X$ axis and $j_{\text {th }}$ or $\mathrm{j}+1_{\text {th }}$ points along the $\mathrm{Y}$ axis, i.e.,

$$
\begin{aligned}
& \frac{\partial \mathrm{K}_{\mathrm{x}}}{\partial \mathrm{t}}=\frac{\mathrm{K}_{\mathrm{x}_{\mathrm{i}}}^{\mathrm{j}+1}+\mathrm{K}_{\mathrm{x}_{\mathrm{i}+1}}^{\mathrm{j}+1}-\mathrm{K}_{\mathrm{x}_{\mathrm{i}}}^{\mathrm{j}}-\mathrm{K}_{\mathrm{x}_{\mathrm{i}+1}}^{\mathrm{j}}}{2 \Delta \mathrm{t}_{\mathrm{j}}}, \\
& \frac{\partial \mathrm{K}_{\mathrm{y}}}{\partial \mathrm{t}}=\frac{\mathrm{K}_{\mathrm{y}_{\mathrm{i}}}^{\mathrm{j}+1}+\mathrm{K}_{\mathrm{y}_{\mathrm{i}+1}}^{\mathrm{j}+1}-\mathrm{K}_{\mathrm{y}_{\mathrm{i}}}^{\mathrm{j}}-\mathrm{K}_{\mathrm{y}_{\mathrm{i}+1}}^{\mathrm{j}}}{2 \Delta \mathrm{t}_{\mathrm{j}}}
\end{aligned}
$$

where $K$ represents variables. The proposed eight point scheme is shown in equation (7) where $\mathrm{P}$ is the variables.

$$
\begin{aligned}
\mathrm{K}_{\mathrm{x}_{\mathrm{i}}}^{\mathrm{j}+1}= & \mathrm{P}_{1} \mathrm{~K}_{\mathrm{x}_{\mathrm{i}-4}}^{\mathrm{j}}+\mathrm{P}_{2} \mathrm{~K}_{\mathrm{x}_{\mathrm{i}-3}}^{\mathrm{j}}+\mathrm{P}_{3} \mathrm{~K}_{\mathrm{x}_{\mathrm{i}-2}}^{\mathrm{j}}+\mathrm{P}_{4} \mathrm{~K}_{\mathrm{x}_{\mathrm{i}-1}}^{\mathrm{j}} \\
& +\mathrm{P}_{5} \mathrm{~K}_{\mathrm{x}_{\mathrm{i}}}^{\mathrm{j}}+\mathrm{P}_{6} \mathrm{~K}_{\mathrm{x}_{\mathrm{i}+1}}^{\mathrm{j}}+\mathrm{P}_{7} \mathrm{~K}_{\mathrm{x}_{\mathrm{i}+2}}^{\mathrm{j}}+\mathrm{P}_{8} \mathrm{~K}_{\mathrm{x}_{\mathrm{i}+3}}^{\mathrm{j}} \\
\mathrm{K}_{\mathrm{y}_{\mathrm{i}}}^{\mathrm{j}+1}= & \mathrm{P}_{1} \mathrm{~K}_{\mathrm{y}_{\mathrm{i}-4}}^{\mathrm{j}}+\mathrm{P}_{2} \mathrm{~K}_{\mathrm{y}_{\mathrm{i}-3}}^{\mathrm{j}}+\mathrm{P}_{3} \mathrm{~K}_{\mathrm{y}_{\mathrm{i}-2}}^{\mathrm{j}}+\mathrm{P}_{4} \mathrm{~K}_{\mathrm{y}_{\mathrm{i}-1}}^{\mathrm{j}} \\
& +\mathrm{P}_{5} \mathrm{~K}_{\mathrm{y}_{\mathrm{i}}}^{\mathrm{j}}+\mathrm{P}_{6} \mathrm{~K}_{\mathrm{y}_{\mathrm{i}+1}}^{\mathrm{j}}+\mathrm{P}_{7} \mathrm{~K}_{\mathrm{y}_{\mathrm{i}+2}}^{\mathrm{j}}+\mathrm{P}_{8} \mathrm{~K}_{\mathrm{y}_{\mathrm{i}+3}}^{\mathrm{j}}
\end{aligned}
$$

where

$$
\begin{aligned}
& \mathbf{P}_{1}=0.01438 \mathbf{a}^{3}-0.08173 \mathbf{a}^{2}+0.06934 a \\
& \mathbf{P}_{2}=-0.01678 a^{3}-0.03899 a^{2}+0.05577 a \\
& \mathbf{P}_{3}=0.25057 a^{3}+0.05914 a^{2}-0.30971 a \\
& \mathbf{P}_{4}=-0.66780 a^{3}+0.63087 a^{2}+1.03693 a \\
& \mathbf{P}_{5}=0.66780 a^{3}-1.37254 a^{2}-0.29527 a+1 \\
& \mathbf{P}_{6}=-0.25057 a^{3}+0.81083 a^{2}-0.56028 a \\
& \mathbf{P}_{7}=0.01678 a^{3}-0.08934 a^{2}+0.07256 a \\
& \mathbf{P}_{8}=0.01438 a^{3}-0.08173 a^{2}+0.06934 a
\end{aligned}
$$

The quality of finite element solution is improved by optimizing the disposition of the nodes. The be fore study relied on their experience to restrict grids that make an efficient use of the available. It is also

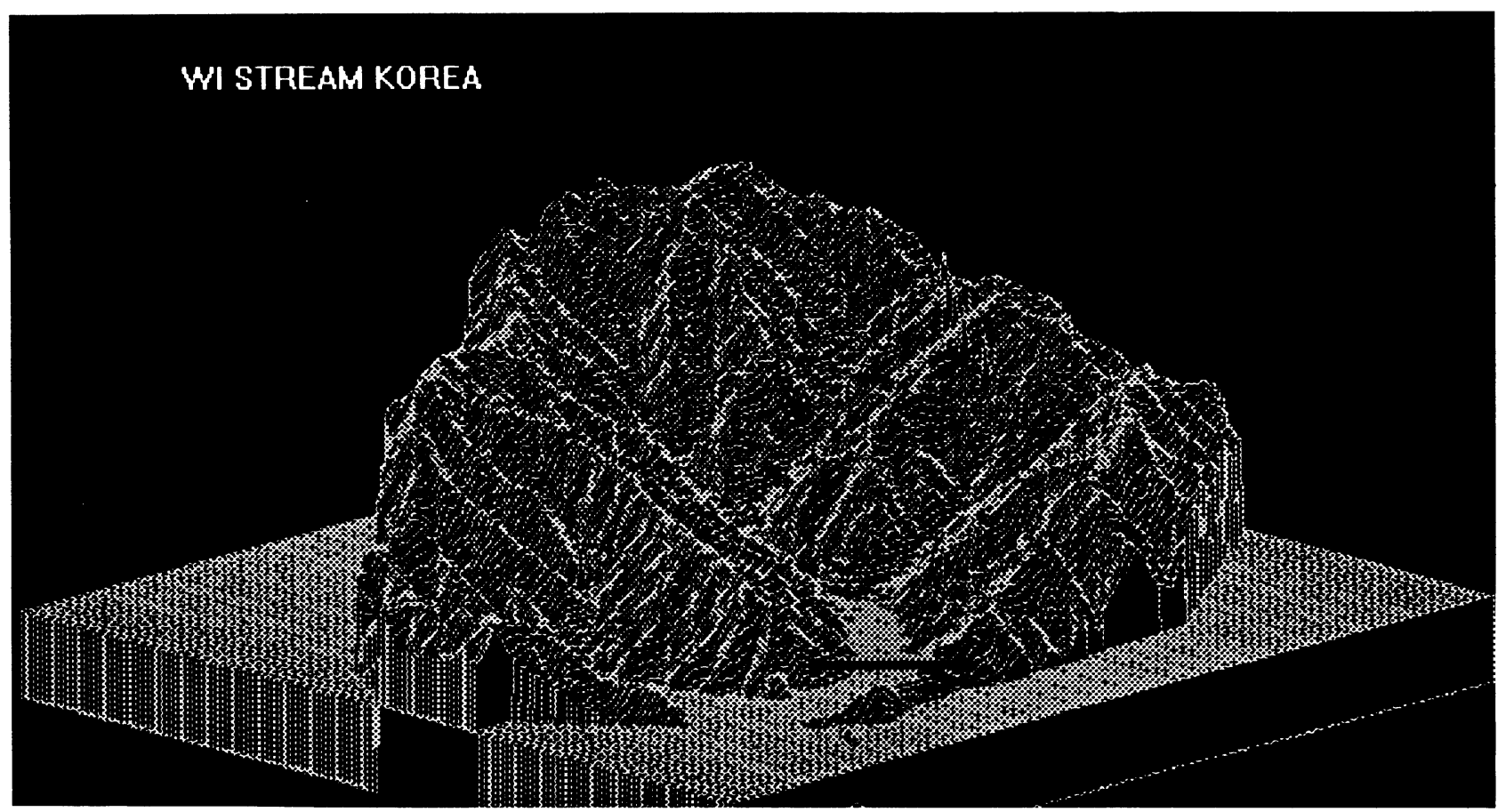

Fig.1 The schematic configuration of applied basin with geometric information system. 
possible to improve the quality of existing meshes it eratively using predefined guidelines for the distribu tion of nodes. The proposed IDP method (Park and Lee, 1995) considers the development of such criterion and the fundamental theory of equation is

$$
\begin{gathered}
-\frac{\partial \overline{\mathrm{F}}}{\partial \mathrm{t}}-\frac{\partial \mathrm{c}}{\partial \mathrm{t}}-\left[\frac{\partial \mathrm{F}_{\mathrm{s}}}{\partial \mathrm{t}}, \Delta \mathrm{s}\right]-0.49\left[\Delta \mathrm{s}, \frac{\partial \mathrm{F}_{\mathrm{ss}}}{\partial \mathrm{t}}, \Delta \mathrm{s}\right]-\text { h.t } \\
=\max \left\{\operatorname{Return}[\overline{\mathrm{s}}+\Delta \mathrm{s}, \overline{\mathrm{u}}+\Delta \mathrm{u}]+<\left(\mathrm{F}_{\mathrm{s}}+\mathrm{F}_{\mathrm{ss}} \Delta \mathrm{s}\right)+\right.\text { h.t. } \\
\phi[\overline{\mathrm{s}}+\Delta \mathrm{s}, \overline{\mathrm{u}}+\Delta \mathrm{u}+\Delta \mathrm{s}>\}
\end{gathered}
$$

$$
\text { where } \quad F_{s}=\frac{\partial F}{\partial s}[\bar{s}+\Delta s, t]=F_{s}[\bar{s}, t]+\overline{F_{s s} \Delta s}
$$$$
\text { and } F_{s}=[\bar{s}+\Delta s, t]=\bar{F}[\bar{s}, t]+c+\left\langle F_{3} \Delta s>\right.
$$

$$
+0.49<\Delta \mathrm{s}, \mathrm{F}_{\mathrm{ss}}, \Delta \mathrm{s}>
$$

where $\mathrm{F}^{*}[\overline{\mathrm{s}}, \mathrm{t}]$ is the optimal maximum return be tween the observed value and computed result of op timal grid size trajectory measured with respect to the trial grid size trajectory form the time to to tf. $\bar{F}$ $[s, t]$ is the return due to the trial grid size $\overline{\mathbf{s}}$ form time to to $t_{f}, c$ is the difference between the maximum return due to the optimal grid size trajectory and the trial grid size trajectory, $\mathrm{F}_{\mathrm{s}}=\left(\frac{\partial \mathrm{F}}{\partial \mathrm{s}_{\mathrm{i}}}, \mathrm{i}=1,2,3, \ldots, \mathrm{m}\right)$, and $F_{s s}=\left(\frac{\partial^{2} F}{\partial s_{i} \partial s_{j}}, i, j=1,2,3, \ldots ., m\right)$. Here $u$ is deci sion vector and $\mathbf{s}$ is state vector.

\section{THE APPLICATION TO THE REAL BASIN}

The applied area in this study is IHP representa tive area which is located southern part of Korea as shown in Figure 1. An assumed grid is $10 \times 10 \mathrm{~m}$ and the initial condition of upstream boundary and down

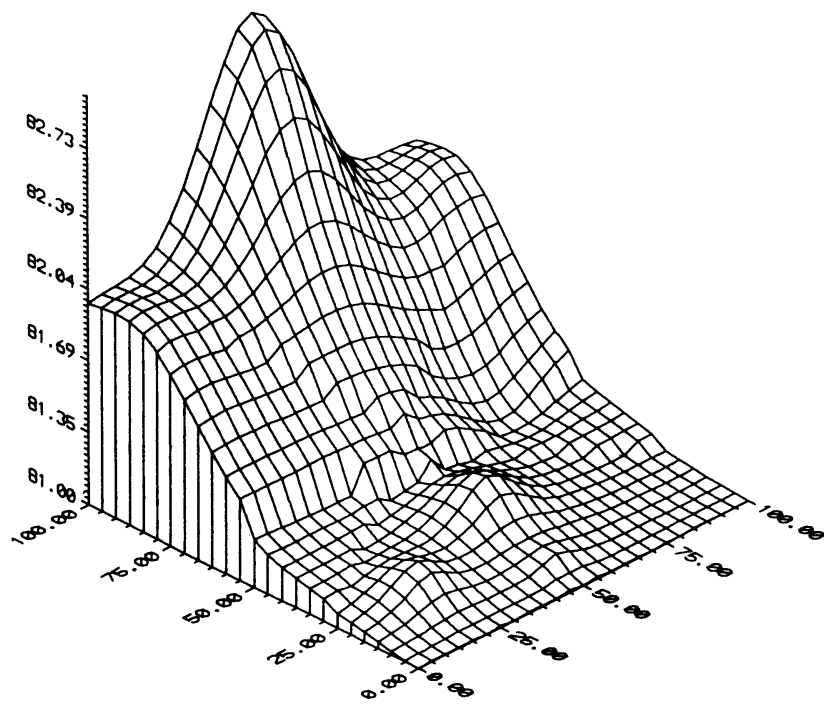

Fig.2 . The steep mountainous area's two dimensional perspective flow view. stream boundary is used by observed data. The exe cuted simulation shows perspective view by grid based geographic analysis system in Figure 2.

The comparison among observed, approximation and conventional model represents good agreement. The computations for the examples presented here was performed on an IBM compatible personal com puter with pentium processor $(133 \mathrm{Mz}$ and Windows95 atmosphere). For each one of the example, the exe cution time was approximately $26 \mathrm{~min} ., 39 \mathrm{~min} .$, re spectively, for the proposed two dimensional approx imation model and general two dimensional models. The different execution times for the approximation and general models are partly due to optimized smaller computation grid adopted with IDP technique, and partly due to faster convergence of numer ical results.

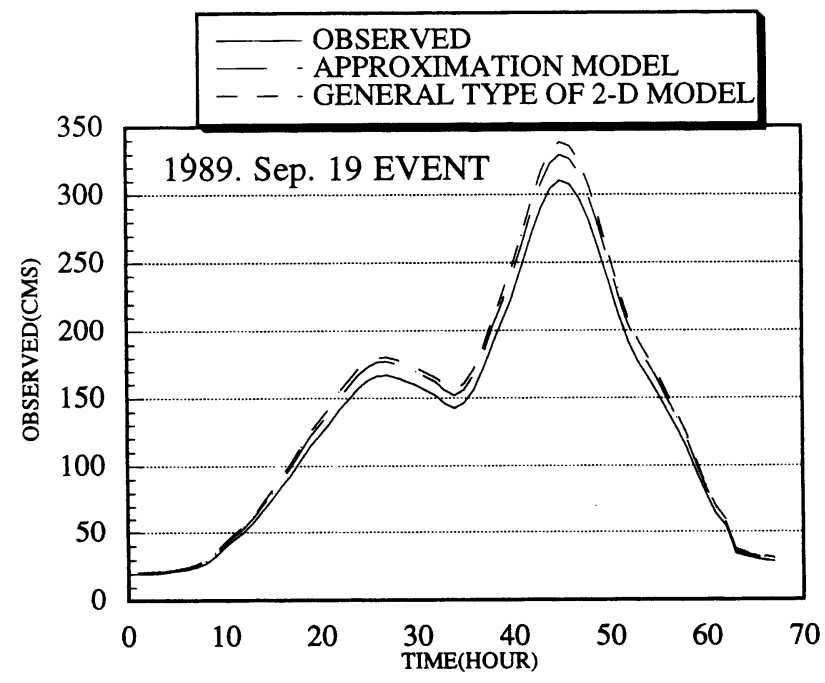

Fig.3 The comparison among observed value, ap proximation and general models.

Through the two dimensional approximation model, the propagation of flood wave front , the veloc ities were computed as shown in Figure 4.

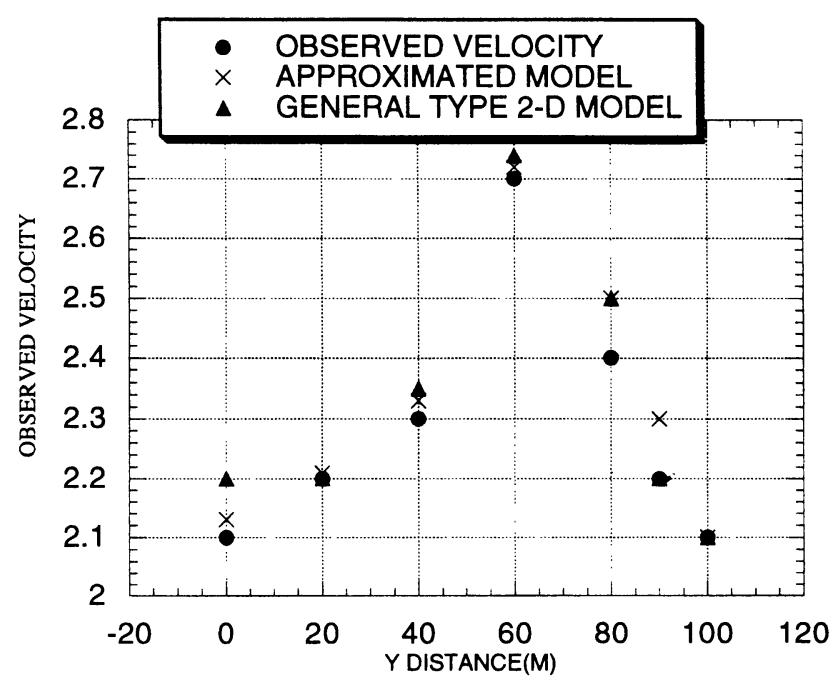

Fig.4 The distribution of velocities and depth. 


\section{CONCLUSION}

The two dimensional model which combined with geometric information system simulates the watershed flow in this study. For the reducing the compu tational time and the simplify formulation, the as sumption of unsteady flow as steady flow is suggest ed. To make accurate and capable a numerical simu lation, the parameter calibration and grid size opti mizing is developed by the use of IDP optimizing technique. Also the proposed eight point scheme can solve the numerical approximation.

The suggested approximated two dimensional model and general type of two dimensional model simulate propagation of flood wave front and the depth and velocities.

The proposed approximated two dimensional model is nearly as accurate the general type of two dimensional model.

The proposed approximated two dimensional model is faster in computation and easier in numeri cal converge due to grid size optimization and simple form of equation.

Therefore the approximated two dimensional model which combined with geometric information system is suggested in this study for the calculation of the flood shock in the real mountainous area and results good applicability.

\section{REFERENCES}

Fennema, Robert J., and Chaudhry, M. Hanif (1989) Implicit methods for two dimensional unsteady free surface flows. Journal of Hydraulic Re search, vol. 27, no. 3, pp. 321 - 332 .

Park, Ki Ho (1995) Hydraulic flood routing for natu ral channels. Journal of Korean Association of Hydrological Science, vol. 28, no. 3, pp. 141 - 150.

Park, Ki Ho (1995) The two dimensional hydrody namic model and its application to real basin's channel routing. AL-AZHAR Engineering Fourth International Conference, Egypt, pp. 628 632.

Park, Ki Ho, and Hirano, Muneo (1995) The propa gation of flood shock model on the steep mountainous area combined with geometrical informa tion system. Abst. 1995 Ann. Conf. Intern. As soc. Math. Geol., Osaka, pp.135-136.

Park, Ki Ho, and Jee, Hong Ki (1994) Channel rout ing with implicit scheme. Technology Reports of Kyushu University, vol. 67, no. 5, pp. 539 - 543.

Park, Ki Ho, and Lee, Soontak (1995) Optimal oper ating rules for integrated reservoir system with IDP in the Nakdong river basin, Korea. Journal of Japan Soc. Hydrol. Water Resour., vol. 8, no. 2, pp. $167-173$. 